ISSN : 2549-2314;

Volume : 1 ; Number 1

\title{
PEMANFAATAN AIR BUANGAN AC (AIR CONDITIONER) SEBAGAI PENGGANTI AKUADES
}

\author{
Samik*, Pirim Setiarso, I Gusti Made Sanjaya \\ Department of Chemistry, Universitas Negeri Surabaya,Ketintang, Surabaya, 60243, Indonesia \\ * Corresponding author, email: samik@unesa.ac.id \\ Co-author 1, email: pirim setiarso@yahoo.co.id \\ Co-author 2, email: igmasanjaya@unesa.ac.id
}

\begin{abstract}
This study successful find quality ( $\mathrm{pH}, T D S$, and conductivity) AC waste water contained in the chemistry department UNESA before and after passing through a column containing Resin Cation Exchanger (RPK) and Resin Anion Exchanger (RPA). The resin was used Aberlite IR 120 resin (Naform) and Aberlite IR 402 resin (Cl-form). AC waste water before passing through the resin has a

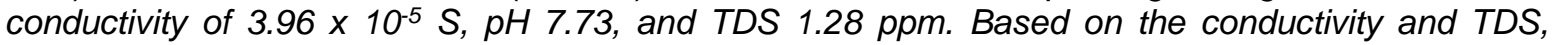
effluent water quality $A C$ after passing through the column contains resins is better than on wastewater $A C$ before passing through the resin. AC waste water after passing through various resin possessed conductivity of $4.4 \times 10^{-6} \mathrm{~S}-2.5 \times 10^{-5} \mathrm{~S}$ and TDS $0.1 \mathrm{ppm}-0.5 \mathrm{ppm}$. The effluent conditioned better quality $\mathrm{pH}$ of distilled water is waste water that has passed through the column AC contains RPK (with a pH between 7.44 -7.62) and conditioned water that passes through the column and then through the column containing RPA contains RPK (with a pH between 7.44 -7.69). $A C$ waste water that has passed through the resin has the quality of distilled water at $\mathrm{pH}$ criteria alone, whereas other criteria (TDS and conductivity) not meet the quality distilled water.
\end{abstract}

Keywords:Air conditioning; wastewater; distilled water; cation-anion exchange resin

\section{ABSTRAK}

Penelitian ini berhasil mengetahui kualitas ( $\mathrm{pH}, T D S$, dan konduktivitas) air buangan AC yang terdapat di jurusan kimia UNESA sebelum dan setelah melewati kolom yang berisi Resin Penukar Kation (RPK) dan Resin Penukar Anion (RPA). Resin yang digunakan adalah resin amberlite tipe IR 120 (bentuk-Na) dan resin amberlite tipe IR 402 (bentuk-Cl). Air buangan AC sebelum melewati resin mempunyai konduktivitas $3.96 \times 10^{-5} \mathrm{~S}, \mathrm{pH}$ 7.73, dan TDS $1.28 \mathrm{ppm}$. Berdasarkan konduktivitas dan TDS, kualitas air buangan AC setelah melewati kolom berisi resin lebih bagus dari pada air buangan $A C$ sebelum melewati resin. Air buangan $A C$ setelah melewati berbagai resin mempunya konduktivitas $4.4 \times 10^{-6} \mathrm{~S}-2.5 \times 10^{-5} \mathrm{~S}$ dan TDS $0.1 \mathrm{ppm}-0.5 \mathrm{ppm}$. Air buangan AC yang kualitas pHnya lebih bagus dari akuades adalah air buangan AC yang telah melewati kolom berisi RPK (dengan pH antara 7.44 -7.62) dan air AC yang melewati kolom berisi RPA lalu melewati kolom berisi RPK (dengan $\mathrm{pH}$ antara 7.44 -7.69). Air buangan AC yang telah melewati resin memiliki kualitas akuades pada kriteria $\mathrm{pH}$ saja, sedangkan kriteria yang lain (TDS dan konduktivitas) belum memenuhi kualitas akuades.

Kata Kunci:AC; limbah cair; akuades; resin penukar kation-anion 


\section{INDONESIAN CHEMISRY AND APPLICATION JOURNAL (ICAJ) 2017 \\ ISSN : 2549-2314; \\ Volume : 1 ; Number 1}

\section{PENDAHULUAN}

Pada zaman modern saat ini, masyarakat telah banyak menggunakan AC (Air Conditioner), baik dalam industri, perumahan, perkantoran, ataupun sekolah sekolah. Air Conditioner merupakan suatu modifikasi pengembangan teknologi mesin pendingin yang dimanfaatkan untuk berbagai tujuan terutama yang bertempat tinggal di wilayah subtropis. Air Conditioner adalah salah satu alat yang memerlukan energi terbanyak kedua setelah alat pemanas [1]. Air Conditioner membantu memberikan udara yang sejuk dan uap air yang dibutuhkan tubuh [2].

Selain menghasilkan udara yang sejuk, AC juga menghasilkan limbah berupa air buangan AC. Air buangan AC tersebut berasal dari udara panas yang diserap dari satu tempat kemudian dikeluarkan ke tempat lain melalui evaporasi (penguapan) dan kondensasi [3]. Kondensasi (pengembunan) udara yang mengandung uap air menghasilkan air dalam bentuk cair. Cairan ini memiliki suhu rendah dan mengandung sedikit mineral [2]. Bila dilihat proses terjadinya air buangan tersebut, maka air AC merupakan air murni yang hampir tidak tercemar oleh elemen - elemen yang mengendap, sehingga bila dibandingkan dengan air hujan, maka sebenarnya air buangan AC lebih bersih.

Air buangan AC umumnya belum dimanfaatkan secara maksimal. Pemanfaatnya terbatas untuk menyiram tanaman, bahkan di beberapa tempat air buangan AC menjadi masalah tersendiri karena membutuhkan penangan khusus ketika berlebih.Padahal air buangan $A C$ dengan kandungan mineral minimum dapat dimanfaatkan sebagai pengganti air radiator mobil dan akuades. Akuades umumnya digunakan untuk berbagai kegiatan medis dan eksperimen.

Penggunaan akuades di laboratorium relatif banyak. Misalkan, keperluan akuades di suatu laboratorium sekitar 1.000 liter/bulan dengan harga akuades yaitu $\mathrm{Rp}$ 1.000/liter, sehingga dana yg diperlukan untuk membeli akuades tiap bulan sekitar Rp 1.000.000. Harga akuades relatif mahal disebabkan karena menggunakan proses destilasi. Destilasi merupakan suatu perubahan cairan menjadi uap dan uap tersebut di dinginkan kembali menjadi cairan. Suatu campuran dapat dipisahkan dengan destilasi untuk memperoleh senyawa murni. Senyawa yang terdapat dalam campuran akan menguap saat mencapai titik didih masing-masing [4].

Proses destilasi melibatkan pemanasan dan pendinginan yang memerlukan biaya relatif mahal sehingga harga akuades relatif mahal. Untuk mengurangi biaya pembelian akuades, maka laboratorium atau perusahaan dapat memanfaatkan air buangan AC yang telah melalui proses pertukaran ion sebagai pengganti air akuades. Pada penelitian terdahulu yang dilakukan oleh Falah dkk. [2] menunjukkan bahwa sampel air AC sebelum dilewati resin yang diambil dari pabrik Cocacola di Ungaran memiliki nilai konduktivitas 78,16 $\mu \mathrm{S}$, padatan terlarut atau TDS 39,1 ppm, pH 5,80 (asam), dan kadar $\mathrm{Pb}$ 0,03 ppm. Setelah melewati resin anion dan kation nilainya menjadi 3,1 $\mu \mathrm{S}$, TDS 1,7 ppm, pH 7,09 dan kadar $\mathrm{Pb}$ 0,00 ppm. Resin yang digunakan adalah resin zerolit 225 (bentuk-Na) sebagai 
penukar ion asam kuat, resin zerolit FF (bentuk-Cl) sebagai penukar ion basa kuat. Ion logam berat yang terdapat di dalam larutan dapat dihilangkan dengan resin penukar ion [5].

Berdasarkan penelitian terdahulu tersebut, maka pada penelitian ini dilakukan proses pertukaran ion yang terdapat dalam air buangan $\mathrm{AC}$ yang terdapat di jurusan kimia UNESA dengan menggunakan resin amberlite tipe IR 120 (bentuk-Na) dan resin amberlite tipe IR 402 (bentuk-Cl) untuk menghasilkan akuades (air murni). Karakteristik air murni dapat diketahui dengan pengukuran konduktivitas, batas maksimal konduktivitasnya $5 \mu \mathrm{S}$ dan $\mathrm{pH}$ nya netral $[2,6,7]$. Untuk mengetahui perbedaan karakter air buangan AC sebelum dan sesudah melewati resin penukar ion, maka dilakukan pengukuran nilai konduktivitas, TDS, dan $\mathrm{pH}$ yang terdapat pada air tersebut.

\section{EXPERIMENTAL}

\section{Material}

Resin penukar kation merek amberlite tipe IR 120 (bentuk-Na), Resin penukar anion amberlite tipe IRA 402 (bentuk-Cl) yang didapatkan dari PT. Brataco, Akuades (kimia farma), Akuademin (kimia farma), $\mathrm{HCl}$ (pa), dan $\mathrm{NaOH}(\mathrm{pa})$.

\section{Instrumentasi}

Kolom penukar ion (Pyrex), statif, Buret (Pyrex), peralatan gelas laboratorium (Pyrex), pipet tetes, $\mathrm{pH}$ meter Martini Instrument, AVOmeter (SUNWA YX-360-TRD), neraca analitis Mettler (Toledo Analytical Balance). Turbidity Meter (MI 415 Merk Martini Instrument)

\section{Prosedur}

Sampel berupa air buangan AC diukur nilai konduktivitas, $\mathrm{pH}$, kadar $\mathrm{Pb}$, dan TDSnya. Tiga kolom dengan panjang $50 \mathrm{~cm}$ dan diameter $2 \mathrm{~cm}$ masing-masing diisi 10 gram resin penukar kation (RPK) yang sudah diaktivasi dengan $\mathrm{HCl}$ (pada kolom I), 10 gram resin penukar anion (RPA) yang sudah diaktivasi dengan $\mathrm{NaOH}$ (pada Kolom II), dan 10 gram RPK yang sudah diaktivasi dengan $\mathrm{HCl}$ ditambah dengan 10 gram RPA yang sudah diaktivasi dengan $\mathrm{NaOH}$ (pada Kolom III). Kolom yang sudah siap masing-masing dialiri $50 \mathrm{~mL}$ sampel dengan laju alir 2 $\mathrm{mL} /$ menit efluen lalu ditampung di botol.Sampel yang sudah melewati kolom masing-masing diukur nilai konduktivitas, $\mathrm{pH}$, dan TDSnya. Langkah di atas diulangi sehingga volume pengambilan (Vp) sampai $500 \mathrm{~mL}$.

\section{HASIL DAN PEMBAHASAN}

Berdasarkan prosesnya, air buangan AC bisa dikatagorikan sebagai akuades. Menurut tim penyusun kamus pusat bahasa [8], akuades adalah air hasil proses penyulingan (Distillation). Untuk memenuhi kriteria seperti akuades, maka air buangan AC dilewatkan resin penukar kation (RPK) dan resin penukar anion (RPA)

Sebelum digunakan, RPK merek amberlite tipe IR 120 (bentuk-Na) diaktivasi dengan $\mathrm{HCl}$ sedangkan RPA merek amberlite tipe IR 402 (bentuk-Cl) diaktivasi dengan $\mathrm{NaOH}$. Reaksi yang terjadi adalah sebagai berikut:

$$
\begin{aligned}
\text { Na-resin }+\mathrm{HCl} & \rightarrow \text { H-resin }+\mathrm{NaCl} \\
\text { Resin- } \mathrm{Cl}+\mathrm{NaOH} & \rightarrow \text { Resin-OH }+\mathrm{NaCl}
\end{aligned}
$$


Setelah diaktivasi, resin tersebut siap digunakan.

Kualitas Air Buangan AC dibandingkan Kualitas Akuademin dan Akuades

Sampel berupa air buangan AC yang ada di Jurusan Kimia UNESA diukur nilai konduktivitas, $\mathrm{pH}$, TDS dan kadar $\mathrm{Pb}$, didapatkan data yang dapat dilihat pada tabel 1 . Sebagai pembanding, diukur juga nilai konduktivitas, $\mathrm{pH}$, dan TDS dari akuademin dan akuades yang ditampilkan pada tabel 2 dan tabel 3.

Tabel 1. Kualitas air buangan AC sebelum melewati resin

\begin{tabular}{ccccc}
\hline $\begin{array}{c}\text { Percobaan } \\
\text { ke- }\end{array}$ & $\begin{array}{c}\text { Konduktivitas } \\
(\mathrm{S})\end{array}$ & $\mathrm{pH}$ & $\begin{array}{c}\text { TDS } \\
(\mathrm{ppm})\end{array}$ & $\begin{array}{c}{[\mathrm{Pb}]} \\
(\mathrm{ppm})\end{array}$ \\
\hline 1 & $4.1666 \times 10^{-5}$ & 7.79 & 1.32 & 0 \\
\hline 2 & $3.7037 \times 10^{-5}$ & 7.71 & 1.21 & 0 \\
\hline 3 & $4.0000 \times 10^{-5}$ & 7.70 & 1.30 & 0 \\
\hline rata-rata & $3.9568 \times 10^{-5}$ & 7.73 & 1.28 & 0 \\
\hline
\end{tabular}

Tabel 2. Kualitas akuademin

\begin{tabular}{cccc}
\multicolumn{4}{c}{ Tabel 2. Kualitas akuademin } \\
\cline { 2 - 4 } $\begin{array}{c}\text { Percobaan } \\
\text { ke- }\end{array}$ & $\begin{array}{c}\text { Konduktivitas } \\
(\mathrm{S})\end{array}$ & $\begin{array}{c}\text { TDS } \\
(\mathrm{ppm})\end{array}$ & $\mathrm{pH}$ \\
\hline 1 & $3.1250 \times 10^{-5}$ & 0.20 & 7.73 \\
\hline 2 & $2.7777 \times 10^{-5}$ & 0.31 & 7.71 \\
\hline 3 & $2.9411 \times 10^{-5}$ & 0.11 & 7.67 \\
\hline rata-rata & $2.9479 \times 10^{-5}$ & 0.21 & 7.70 \\
\hline
\end{tabular}

Tabel 3. Kualitas akuades

\begin{tabular}{cccc}
\hline \multirow{2}{*}{$\begin{array}{c}\text { Percobaan } \\
\text { ke- }\end{array}$} & $\begin{array}{c}\text { Konduktivitas } \\
(\mathrm{S})\end{array}$ & $\begin{array}{c}\text { TDS } \\
(\mathrm{ppm})\end{array}$ & $\mathrm{pH}$ \\
\cline { 2 - 4 } & $2.0000 \times 10^{-6}$ & 0.25 & 7.90 \\
\hline 1 & $2.0000 \times 10^{-6}$ & 0.42 & 7.69 \\
\hline 3 & $1.9607 \times 10^{-6}$ & 0.07 & 7.49 \\
\hline rata-rata & $1.9869 \times 10^{-6}$ & 0.25 & 7.69 \\
\hline
\end{tabular}

Sampel air buangan AC tidak mengandung $\mathrm{Pb}$, hal ini ditunjukkan dengan kadarnya 0 ppm. Berdasarkan tabel 1 dan 2 diketahui bahwa kualitas air buangan AC sebelum perlakuan (sebelum melewati resin) memiliki kualitas yang berbeda dengan akuademin dan akuades. Nilai konduktivitas, $\mathrm{pH}$, dan TDS air buangan AC lebih besar dibandingkan dengan konduktivitas, $\mathrm{pH}$, dan TDSnya akuademin dan akuades. Konduktivitas air buangan AC (3.96 x 10-5 S) lebih besar dibandingkan dengan akuademin $\left(2.95 \times 10^{-5} \mathrm{~S}\right)$ dan akuades $\left(1.99 \times 10^{-6} \mathrm{~S}\right)$. Hal ini menunjukkan kemampuan mengantarkan arus listrik yang lebih besar pada air buangan AC dibandingkan akuademin dan akuades.

Selisih $\mathrm{pH}$ air buangan $\mathrm{AC}$ dengan akuademin dan akuades sekitar 0.03-0.04. Ini menunjukkan bahwa $\mathrm{pH}$ air buangan $\mathrm{AC}$ memiliki kualitas yang hampir sama dengan akuademin dan akuades. $\mathrm{pH} 7.73$ dari air buangan AC menunjukkan air tersebut bersifat sedikit basa (hampir netral). Nilai TDS (total dissolved solid) air AC dibandingkan dengan akuademin dan akuades lebih besar sekitar 1 ppm.Ini berarti benda padat yang terlarut (seperti mineral, garam, logam, serta kationanion yang terlarut di air) di dalam air buangan AC lebih banyak dibandingkan di akuademin dan akuades.

Secara umum dapat disimpulkan kualitas konduktivitas, $\mathrm{pH}$, dan TDS air buangan AC relatif bagus karena tidak jauh beda dengan kualitas akuademin dan akuades. Hal ini dikarenakan air buangan AC tersebut berasal dari kondensasi (pengembunan) udara sekitar yang mengandung uap air menghasilkan air dalam bentuk cair.Bila dilihat proses terjadinya air buangan tersebut, maka air AC merupakan air murni yang hampir tidak tercemar oleh elemen - elemen yang mengendap, sehingga 
bila dibandingkan dengan air hujan atau air tanah, maka sebenarnya air buangan AC lebih bersih.

\section{Kualitas Air Buangan AC setelah Melewati RPK dan RPA}

Sampel berupa air buangan AC dilewatkan tiga kolom yang berbeda supaya terjadi pertukaran ion, kolom pertama berisi RPK merek amberlite tipe IR 120 (bentuk Na) yang sudah diaktivasi dengan $\mathrm{HCl}$, kolom kedua berisi RPA merek amberlite tipe IRA 402 (bentuk $\mathrm{Cl}$ ) yang sudah diaktivasi dengan $\mathrm{NaOH}$ dan kolom ketiga berisi RPA dan RPK.
Pertukaran ion merupakan proses dimana suatu larutan dilewatkan melalui kolom yang berisi zat yang tidak dapat larut (material padat) sehingga zat tersebut dapat mengambil ion bermuatan positif atau negatif dari larutan elektrolit dan melepaskan ion bermuatan sejenis ke dalam larutan yang secara kimiawi jumlahnya sama $[9,10]$. Proses pertukaran ion ini tidak menyebabkan perubahan struktur fisik dari resin penukar ion [11].

Nilai konduktivitas, $\mathrm{pH}$, dan TDS air buangan AC setelah melewati kolom yang berisi resin yang berbeda-beda dapat dilihat secara berturut-turut pada gambar 1, 2 dan 3 .

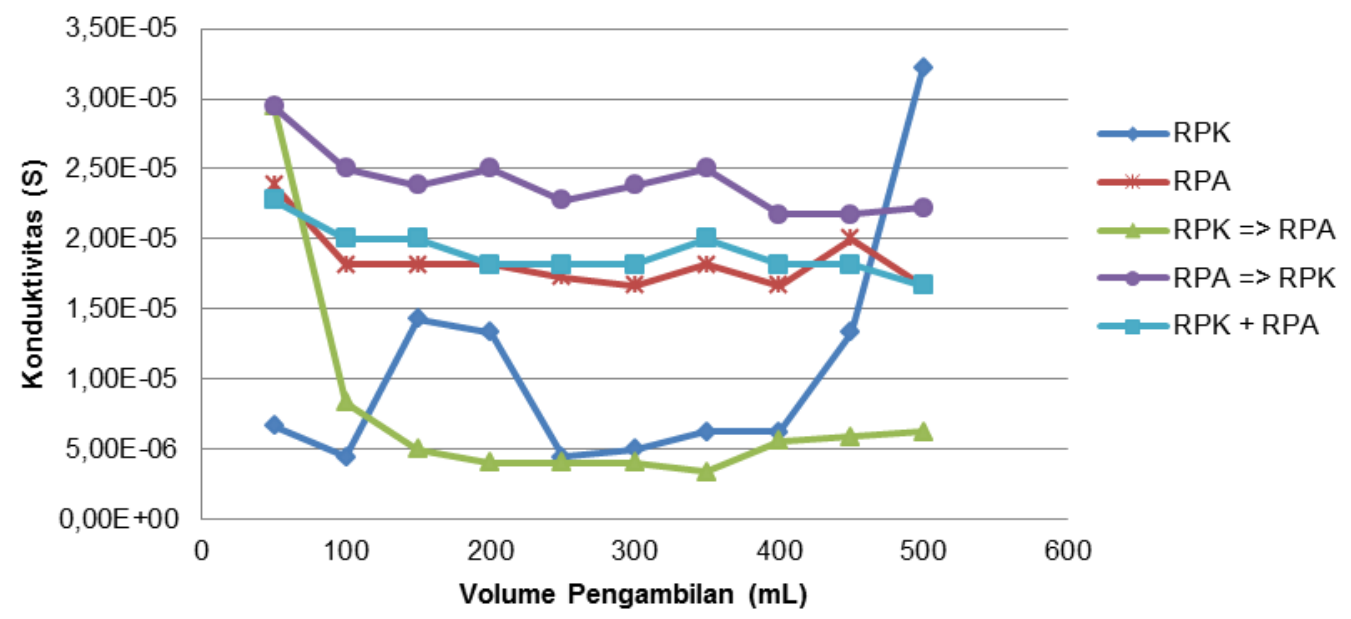

Gambar 1. Hubungan konduktivitas dengan volume pengambilan pada sampel air buangan ACsetelah melewati kolom yang berisi berbagai jenis resin

Secara umum, gambar 1 menunjukkan bahwa konduktivitas sampel air buanagn $A C$ yang telah melewati kolom yang berisi berbagai jenis resin dengan volume pengambilan antara 50 - $500 \mathrm{~mL}$ mempunyai konduktiivitas antara $4.4 \times 10^{-6} \mathrm{~S}$ sampai dengan $2.5 \times 10^{-5} \mathrm{~S}$. Konduktivitas tersebut lebih rendah dari pada konduktivitas air buangan AC sebelum melewati resin yaitu $3.9 \times 10^{-5} \mathrm{~S}$. Hal ini menunjukkan bahwa berbagai jenis resin tersebut mampu menggantikan berbagai ion pengotor di dalam air buangan AC sehingga air buangan AC yang telah melewati resin mempunyai konduktivitas yang lebih rendah (kemampuan larutan untuk mengalirkan arus listrik lebih rendah). Kemampuan resin penukar kation dan anion dalam menukar ion juga dilaporkan oleh Edebali dkk [12] dan Li dkk [13]. Kemampuan ini tergantung pada kehadiran ion-ion, konsentrasi total ion, 
mobilitas, dan valensi, serta temperatur pada saat pengukuran. Penghantaran arus listrik terjadi karena perpindahan ion-ion bermuatan [2].

Gambar 2 menggambarkan hubungan $\mathrm{pH}$ dengan volume pengambilan pada sampel air buanagn $\mathrm{AC}$ setelah melewati kolom yang berisi berbagai jenis resin. Berdasarkan gambar tersebut, diketahui bahwa pHnya antara 7.4 sampai dengan 7.9.pH air buangan
AC sebelum melewati resin adalah 7.73. Sedangkan $\mathrm{pH}$ akuademin dan akuades yang ada di jurusan kimia UNESA berturut-turut adalah 7.70 dan 7.69. Air buangan AC yang kualitas pHnya lebih bagus dari akuades dan akuademin adalah air buangan AC yang telah melewati kolom berisi RPK (dengan pH antara 7.44 -7.62) dan air AC yang melewati kolom berisi RPA lalu melewati kolom berisi RPK (dengan pH antara 7.44 -7.69).

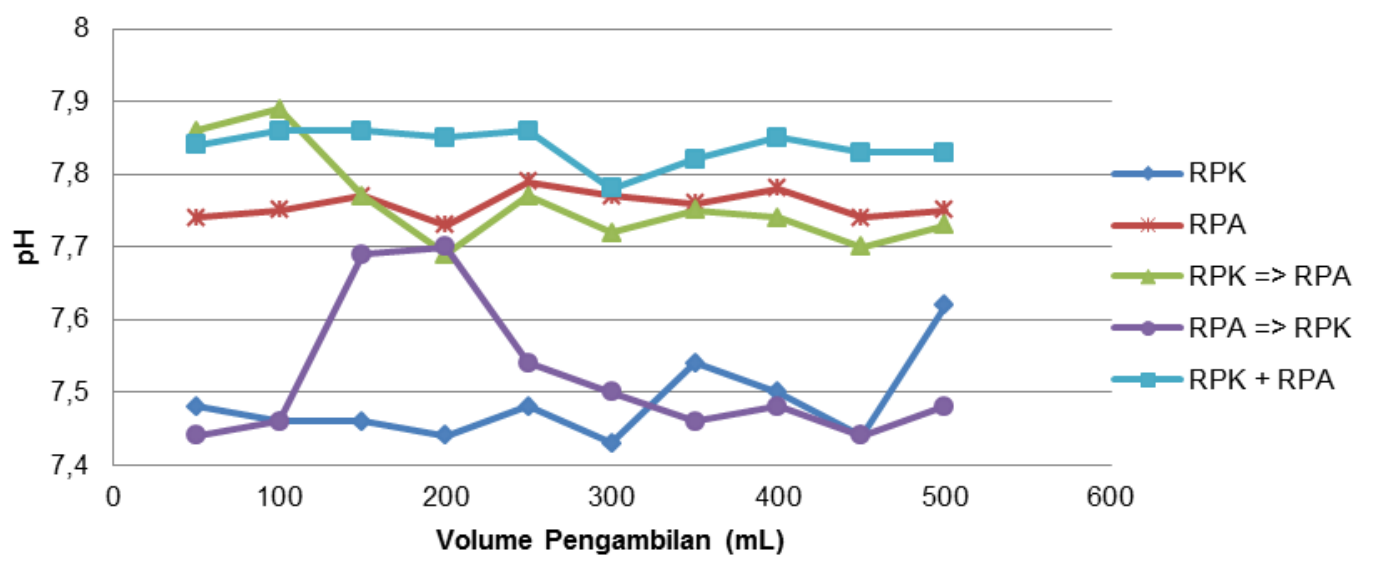

Gambar 2 Hubungan $\mathrm{pH}$ dengan volume pengambilan pada sampel air buanagn AC setelah melewati kolom yang berisi berbagai jenis resin

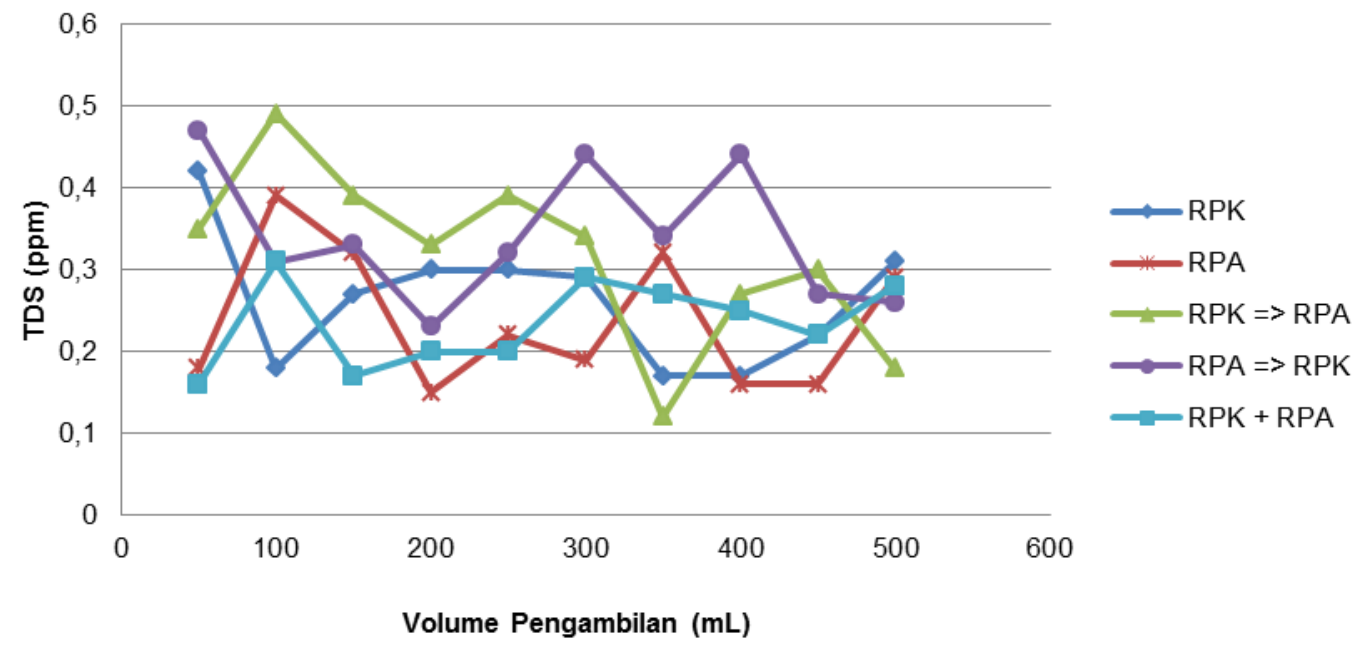

Gambar 3. Hubungan TDS dengan volume pengambilan pada sampel air buanagn AC setelah melewati kolom yang berisi berbagai jenis resin 
ISSN : 2549-2314;

Volume : 1 ; Number 1

Gambar 3 menunjukkan bahwa Total Disolved Solid (TDS) sampel air buanagn AC yang telah melewati kolom yang berisi berbagai jenis resin dengan volume pengambilan antara 50 - $500 \mathrm{~mL}$ mempunyai nilai TDS antara 0.1 $0.5 \mathrm{ppm}$. Hal ini menunjukkan jumlah padatan terlarut dalam air buangan AC yang telah melewati resin lebih kecil dari pada air buangan AC sebelum melewati resin. TDS air buangan AC sebelum melewati resin sekitar 1.28 ppm, sedangkan TDS akuademin dan akuades adalah 0.21 dan 0.25 ppm. RPA dan RPK yang digunakan terbukti mampu menyaring padatan terlarut sehingga nilai TDSnya turun. Penurunan nilai TDS air yang telah melewati resin juga dilaporkan oleh Partuti [14]. Ratarata nilai TDS air $\mathrm{AC}$ yang telah melewati resin lebih tinggi dari akuademin dan akuades menunjukkan bahwa air tersebut belum memenuhi kualitas akuademin maupun akuades.

\section{KESIMPULAN}

Penelitian ini berhasil mengetahui kualitas air buangan AC yang terdapat di jurusan kimia UNESA sebelum dan setelah melewati kolom yang berisi RPK dan RPA. Resin yang digunakan adalah resin amberlite tipe IR 120 (bentuk-Na) dan resin amberlite tipe IR 402 (bentuk-Cl). Air buangan AC sebelum melewati resin mempunyai konduktivitas $3.96 \mathrm{x}$ $10^{-5} \mathrm{~S}$, pH 7.73, dan TDS 1.28 ppm. Berdasarkan konduktivitas dan TDS, kualitas air buangan $\mathrm{AC}$ setelah melewati kolom berisi resin lebih bagus dari pada air buangan $A C$ sebelum melewati resin. Air buangan AC setelah melewati berbagai resin mempunya konduktivitas $4.4 \times 10^{-6} \mathrm{~S}-2.5 \times 10^{-5} \mathrm{~S}$ dan TDS $0.1 \mathrm{ppm}-0.5 \mathrm{ppm}$. Air buangan AC yang kualitas pHnya lebih bagus dari akuades adalah air buangan $\mathrm{AC}$ yang telah melewati kolom berisi RPK (dengan pH antara 7.44 7.62) dan air $A C$ yang melewati kolom berisi RPA lalu melewati kolom berisi RPK (dengan $\mathrm{pH}$ antara 7.44 -7.69). Air buangan AC yang telah melewati resin memiliki kualitas mirip akuades pada kriteria $\mathrm{pH}$ saja, sedangkan kriteria yang lain (TDS dan konduktivitas) belum memenuhi kualitas akuades.Pada penelitian berikutnya perlu dilakukan penukaran kation anion air buangan AC dengan menggunakan resin yang lain (seperti zerolit) dan merancang alat yang aplikatif untuk produksi akuades dari air buangan AC secara masal.

\section{UCAPAN TERIMA KASIH}

Penulis menyampaikan rasa terima kasih yang sebesar-besarnya kepada pimpinan FMIPA UNESA dan LPPM UNESA atas pendanaan penelitian ini, sehingga penelitian ini berjalan lancar.

\section{DAFTAR PUSTAKA}

[1] Fayazbakhsh, M.A., Bagheri, F., Bahrami, M., "An Inverse Method for Calculation Of Thermal Inertia and Heat Gain in Air Conditioning and Refrigeration Systems", Applied Energy, Volume 138, pp. 496-504, 2015.

[2] Falah, L. M., Gunawan, dan Haris, A., "Pembuatan Aquadm (Aquademineralized) Dari Air AC (Air Conditioner) Menggunakan Resin Kation Dan Anion", S.Si. Tugas akhir, Universitas Diponegoro, Semarang, Indonesia, Feb. 2009.

[3] Sarbu, I., "A review on substitution strategy of nonecological refrigerants from vapour compressionbased refrigeration, air-conditioning and heat pump 
systems", International Journal of Refrigeration, Volume 46, pp 123-141, 2014.

[4] Walangare, K. B. A., Lumenta, A. S. M., Wuwung, J. O., Sugiarso, B. A., \& Unsrat, J. T. E. ft. "Rancang Bangun Alat Konversi Air Laut Menjadi Air Minum Dengan Proses Destilasi Sederhana Menggunakan Pemanas Elektrik", e-Jurnal Teknik Elektro dan komputer, Volume 2, pp. 1-11. 2013.

[5] Dzyazko, Y.S., Volfkovich, Y.M., Ponomaryova, L.N., Sosenkin, V.E., Trachevskii, V.V., Belyakov, V.N., "Composite Ion-Exchangers Based On Flexible Resin Containing Zirconium Hydrophosphate for Electromembrane Separation", Journal of Nanoscience and Technology, Volume 2, pp 43-49, 2016.

[6] Boulanger, L. "Observations on Variations in electrical conductivity of pure demineralized water: modification of conductivity by low-frequency alternativing electric fields", Int J Biometeorol, Volume 41, pp. 37-140, 1997.

[7] Lestari, D. E., dan Utomo, S. B., "Karakteristik Kinerja Resin Penukar Ion pada Sistem Air Bebas Mineral (GCA) RSG-GAS", Seminar Nasional III SDM Teknologi Nuklir, 2007, paper, pp. 95-104

[8] Tim Penyusun Kamus Pusat Bahasa, Kamus Bahasa Indonesia, Jakarta, Indonesia: Pusat Bahasa, 2008

[9] Ebbing, D. D., dan Gammon, S. D., General Chemistry, Boston New York, USA: Houghton Mifflin Company, 2009

[10] Inglezakis, V. J., dan Poulopoulos, S. G., Adsorption, Ion Exchange and Catalysis Design of Operations and Environmental Applications, Amsterdam, Belanda Elsevier, 2006

[11] Grinstead, R.R. dan Pallman, H.H., "Metal Ion Scavenging from Water with Fine Mesh Ion Exchange and Micropous Membranes", Environmental Progress. Volume 8, pp. 35-39, 1989

[12] Edebali, S. dan Pehlivan, E., "Evaluation of chelate and cation exchange resins to remove copper ions", Powder Technology, Volume 301, pp. 520-525, 2016.

[13] Li, H.Y., Li, C., Zhang, M., Wang, K., dan Xie, B., "Removal of $\mathrm{V}(\mathrm{V})$ from aqueous $\mathrm{Cr}(\mathrm{VI})$-bearing solution using anion exchange resin: Equilibrium and kinetics in batch studies", Hydrometallurgy, Volume 165, pp 381-389, 2016

[14] Partuti, T., "Efektivitas Resin Penukar Kation untuk Menurunkan Kadar Total Dissolved Solid (TDS) dalam Limbah Air Terproduksi Industri Migas", Jurnal Integrasi Proses, Vol. 5, NO. 1, pp. 1- 7, 2014 